\title{
O PERCURSO TRAUMÁTICO DO HERÓI CONTEMPORÂNEO EM LONGE DA ÁGUA, DE MICHEL LAUB
}

\author{
Luiza Casanova Machado ${ }^{1}$ \\ Vera Lucia Lenz Vianna ${ }^{2}$
}

\begin{abstract}
Resumo: Longe da Água (2004) é o romance do escritor porto-alegrense Michel Laub. Com a finalidade de investigar como se dá a tensão entre a trajetória individual da personagem da obra do escritor gaúcho, contra uma força que insiste em determinar o seu percurso, a obra será pensada através de textos críticos que abordam a produção literária contemporânea brasileira e ocidental, em especial a narrativa, e que mapeiam seus principais traços e tendências, como, por exemplo, Karl Erik Schollharmmer (2011; 2013), Michel Maffesoli (2003) e Tânia Pellegrini (2008). A partir dessa questão é que será possível compreender de que maneira o tempo em Longe da Água nos mostra segundos e são contados dolorosamente, em um processo de escritura o qual se detém nos detalhes (nas minúcias do cotidiano), na busca incessante por explicações, na reconstrução do passado, na necessidade de entender as motivações por trás de certos atos (atitudes) de determinadas personagens e as consequências que conduzem a narrativa e ganham consistência de realidade imposta e impossível de fuga.
\end{abstract}

Palavras-chave: Literatura; narrativa; indivíduo; destino; percurso existencial.

Abstract: Longe da Água is a novel by the portoalegrense Michel Laub. In order to investigate the way tension is created along the individual trajectory of the writer's character and the force he faces that insists in determining his path, texts of criticism about Brazilian and Western contemporary literary production will lend theoretical support to the analysis; especially those that focus the narrative and map out its major traits and tendencies. Books by Erik Schollharmmer $(2011 ; 2013)$, Michel Maffesoli (2003) and Tania Pellegrini(2008) are some examples.We believe that such starting point enables us to understand the way time, in Longe da Água, dispalys the seconds which are painfully narrated, in a writing process where details are emphasized (the trivialities of daily life), in the continuous search for explanations, in the reconstruction of the past, in the need to comprehend the hidden motivations of some of the characters' attitudes and the consequences that lead the narrative and gain a consistency of imposed reality and no possibility of scape.

Keywords: Literature; narrative; the individual; destiny; existential trajectory.

\footnotetext{
${ }^{1}$ Mestranda do Programa de Pós-Graduação em Estudos Literários da Universidade Federal de Santa Maria. E-mail: Icmcasanova@gmail.com.

${ }^{2}$ Doutora em Letras pela Universidade Federal do Rio Grande do Sul. Atualmente é professora Associado 1 da Universidade Federal de Santa Maria. Tem experiência na área de Letras, com ênfase em Literatura Anglo- Americana e brasileira e língua inglesa. Atua principalmente nos seguintes temas: literatura e Figurações da Alteridade, identidade cultural, ideologia, entre outros. E-mail: lenzvl@gmail.com
} 
O corpus da Literatura brasileira contemporânea, a qual vem revelando jovens escritores nos últimos anos, entre outros aspectos, identifica-se pelo fato de ter ganhado novos suportes e novos formatos, principalmente, através da internet. Um exemplo da ampliação dessas fronteiras e das novas vias de circulação da produção literária atual é o percurso do jovem autor Daniel Galera, que iniciou sua carreira na Literatura publicando em blogs na internet, como, por exemplo, o Cardoso online, e, em seguida, fundou sua própria editora ao lado de Daniel Pellizzari e Guilherme Pilla, a Livros do Mal, de Porto Alegre, na qual lançou seu primeiro livro (Dentes Guardados, 2001) e publicou também outros autores com planos de fincar os pés no cenário literário atual.

Assim como muitos desses autores que começaram a vida literária publicando em pequenas editoras ou na internet e logo depois fizeram sucesso em editoras de maior projeção, como, por exemplo, a Companhia das Letras, está o porto-alegrense Michel Laub, que nasceu em 1973, na capital gaúcha e que vive em São Paulo, atualmente.

Autor de Não depois do que aconteceu (contos, 1998), Música anterior (romance, 2001) pelo qual recebeu o Prêmio Érico Veríssimo da União Brasileira de Escritores na categoria revelação, Longe da Água (romance, 2004), O Segundo Tempo (romance, 2006) que foi contemplado com uma bolsa da Fundação Vitae, O Gato diz Adeus (romance, 2009) e Diário da Queda (romance, 2011) escrito com apoio de uma bolsa da Funarte. Essa última foi sua primeira obra a abordar a temática judaica como elemento principal da narrativa e que foi escrita a partir de diários de um sobrevivente do campo de concentração de Auschwitz, e A Maçã Envenenada (romance, 2013). Todos os romances acima mencionados foram publicados pela editora Companhia das Letras.

Mirando essas quase duas décadas de trajetória literária, centramo-nos na produção ficcional do autor, na qual identificamos não somente uma reunião de títulos, como também um possível ponto em comum que parece caracterizá-los: a linguagem das obras narrativas de Laub reflete uma 
sensibilidade para captar acontecimentos aparentemente sem grande dramaticidade, ou consistência, na medida em que os dramas diários são o suficiente para desencadear consequências dramáticas, ou trágicas.

As narrativas do autor Michel Laub, especificamente o relato de Longe da água, apresentam personagens e situações que são a representação de outro tempo, um tempo que destoa, um tempo em que os segundos e os minutos são contados em um relógio que marca não só a passagem do tempo, mas também as cicatrizes causadas por ele. Eventos que se sobrepõem e que se ressignificam, transformando o relógio em uma ampulheta de areia espessa, passando devagar de uma extremidade do vidro cilíndrico até a outra para, quando a areia que desce acabar, se fundir toda em uma só.

O tempo da ampulheta talvez seja o mesmo tempo marcado em um relógio comum, a diferença é que aquele tempo é visualizado grão por grão, ou seja, é possível visualizar seu movimento de descida. Nas ampulhetas do tempo de Longe da água, a temporalidade é um mistério e pode ser tomada como uma concepção da existência humana, pois: o tempo é concepção estética e é destino (aquilo que está posto e pré-determinado), revelando-se como um mistério e como uma concepção da existência humana. O destino traçado é anterior ao homem, é ampulheta de areia presa, e é este ponto que recairá sobre a questão de pesquisa.

A partir da observação crítica pontual de certos aspectos composicionais da obra é possível perceber uma busca incessante por explicações para fatos que, de início, podem parecer simples coincidências, mas que, no decorrer do relato, se mostram como uma força intransponível do destino. Situações semelhantes que vão se transformando em traumas, traumas que tentam ser superados, superações que não chegam a lugar algum, a não ser o lugar da tragédia final. Um destino marcado. Um sujeito marcado, que faz suas escolhas e toma decisões na sua consciência de ser possuidor de livre arbítrio, mas que vê o destino se metendo por entre as frestas das escolhas e indo mais a frente. Lá adiante esse sujeito ficcional se encontrará com a prestação de contas com o não-acaso, com a não-escolha, com a não-coincidência, com a tragédia 
anunciada desde o início, mas que, mesmo sendo anunciada desde o sempre, não pode ser deixada para trás, nem mesmo ultrapassada ou superada.

Diante da força das manifestações realistas e da contundência dessa vertente para a Literatura brasileira, é necessário entender o que ela é e como ela constitui-se socioculturalmente e literariamente. Outrossim, é importante construir uma significação dessas manifestações através das suas diferenças em relação aos sistemas literários de diversos países em que o Realismo vigorou não somente como estilo de época, mas também como estética da e na Literatura subsequente.

O Realismo, enquanto corrente literária, toma proporções na França do século XIX, no auge do Positivismo, espalhando-se pelo Ocidente, e, desde então tem sido utilizado para definir qualquer representação artística a qual se disponha a reproduzir o mundo concreto e suas configurações. Entende-se que o Realismo surgiu de um processo histórico social específico, que foi a realidade oitocentista, e corresponde ao poder crescente da classe burguesa.

Em Ascensão do Romance, lan Watt (1957, p. 34) assinala que o Realismo formal caracteriza-se pelo método narrativo responsável pela incorporação de uma visão circunstancial da vida à Literatura. Watt também afirma que a ideia de forma sustenta o conceito de Realismo, uma vez que ele não se define, simplesmente, pelos tipos de vidas representadas, mas pela maneira como as apresenta. O elemento definidor é, então, a forma como a narrativa vai representar as histórias, portanto, não se trata do tipo de vida representada, mas sim sob qual perspectiva ela é narrada; maneira pelo qual o Realismo é compreendido como:

Um conjunto de procedimentos narrativos [...] organizados segundo a premissa de que o romance constitui um relato completo e autêntico da experiência humana e, portanto, tem a obrigação de fornecer aos leitores detalhes da história como a individualidade dos agentes envolvidos, os particulares das épocas e os locais de suas ações-detalhes que são apresentados através de um emprego da linguagem muito mais referencial do que é comum em outras formas literárias. (WATT, 1996, p. 34) 
O teórico em questão, ainda, considera que há diferentes formas literárias para se imitar a realidade, porém, é no e com o Realismo formal que acontece a mimese (mimesis) mais imediata da experiência individual em um dado contexto espaço-temporal. Através desse ponto de vista, o Realismo pode ser interpretado como um procedimento narrativo passível de ser incorporado por qualquer época, em vista de sua natureza transformável, mutável e aberta, o que, certamente, acarretaria uma maior adesão do público leitor em um processo de reconhecimento com a busca por totalidade (movimento do herói romanesco).

A partir das reflexões feitas por Mikhail Bakhtin em "Epos e romance" (2010, p. 400), ensaio no qual se evidencia o romanesco como um gênero em "construção, acanônico e inacabado", isto é, o romance como o único gênero literário capaz de estar alinhado organicamente a novas formas de recepção, ou seja, à leitura, em suma.

Em tal sentido, entendemos o romance como um gênero ainda em plena evolução: "por isso ele reflete mais profundamente, mais substancialmente, mais sensivelmente e mais rapidamente a evolução da própria realidade" (BAKHTIN, 2010, p. 400). Dessa forma, há uma imbricação histórica do gênero romanesco com a época que permite sua formação e sua consolidação, a Modernidade, mesmo que ela viva hoje uma etapa de declínio ou, de morte:

Somente o que evolui pode compreender a evolução. O romance tornou-se a principal personagem do drama da evolução literária na era moderna precisamente porque, melhor que todos, é ele que expressa as tendências evolutivas do novo mundo, ele é, por isso, o único gênero nascido no mundo e em tudo semelhante a ele [...]. Deste modo tornando-se o senhor, ele contribui para a renovação de todos os outros gêneros, ele os contaminou e os contamina por meio de sua evolução e pelo seu próprio inacabamento. (BAKHTIN, 2010, p. 400)

Esse inacabamento confere ao romance uma natureza capaz de the permitir uma transformação constante, para assim poder representar 0 
momento histórico, o momento social e o momento cultural no qual cada obra é produzida, ou também representar um anacronismo frente às tendências dos períodos em que estão encaixados, para, então, representá-los.

A leitura de Bakhtin implica no entendimento de que o Realismo acomodou-se ao gênero romance por compactuar com a maleabilidade desse e por eleger o indivíduo como centro da narração. A forma inacabada confere ao romance uma natureza plástica, capaz de lhe permitir uma transformação constante, para assim poder representar o momento histórico, social e cultural no qual cada obra é produzida.

Destarte, ao considerarmos que o Realismo, em uma definição simplificada, é a representação da realidade, é inegável que as mudanças dessa realidade (acontecidas e provocadas por ela) acarretam diferentes representações dela na arte literária. Assim, um romance contemporâneo passa a incorporar tendências desse período e representá-las.

A relação entre mundo e Literatura sempre foi preocupação das correntes teóricas e, desse modo, o conceito de representação literária é questionado. Alguns teóricos acreditavam que a Literatura não tinha nenhuma relação com a realidade enquanto outros defendiam aquela como uma cópia da realidade, ou do "real"2. Porém, essas visões não abarcam todas as concepções de teoria literária, já que parece extremista e reducionista compreender a Literatura apenas sob o jugo desse dualismo (sem relação com o real e imitação do real).

Para os fins do nosso estudo, a representação será vista como o trabalho de um sujeito que está inserido no mundo, que vê o mundo e que o transforma a partir de sua leitura única, individual e intransferível. Processo de mão dupla, pois o sujeito constrói-se a partir do mundo e, ao mesmo tempo, constrói o mundo e outros mundos possíveis.

\footnotetext{
2 Aqui, tratamos do conceito de real a partir das teorizações lacanianas sobre tal (LACAN, 1992). Assim, sumariamente, o real está para tudo aquilo que não é imaginário, ou simbólico, ou seja, o real é a totalidade que escapa a semiotizações. 
Em termos de representação da realidade e, por conseguinte, do Realismo, apresentaremos sem grandes pormenores os pontos desse debate que é amplo. Para tanto, exploraremos o ponto de vista de Antoine Compagnon em O Demônio da Teoria (1998), mais precisamente no capítulo intitulado $O$ Mundo, no qual são apresentadas as duas principais posturas teóricas que convergem no que diz respeito ao que a Literatura representa.

De um dos lados está a representação mimética, ou referencial, a qual entende as imagens e os signos como ligados a referentes, a temas icnográficos, ou às coisas reais, pertencente ao mundo da experiência. Do outro lado do debate está a representação simulacral, ou semiosis, que entende as imagens como meras representações de outras imagens, o que converte todo o sistema de representação, inclusive o Realismo, em um sistema autorreferencial. Compagnon assenta seu posicionamento na relação da representação com um referente, indicando que a questão está no como esta representação se dá.

Para Schollhammer (2011), o Realismo hoje, é um acontecimento discursivo que se dá em uma estranha combinação entre a representação e a não representação. O crítico literário sobredito defende a "estética do afeto" em oposição à "estética do efeito", estando, na ordem do dia, as narrativas que conciliam as vertentes experimentalistas das vanguardas e a vertente realista engajada. Como se fosse o real, a prosa contemporânea cria uma experiência com o real através da experiência performática da linguagem, criando uma ligação afetiva, e, por conseguinte, criando, dessa maneira, o caminho para outro tipo de Realismo: "cuja realidade não se apoia na verossimilhança da descrição representativa, mas no efeito estético da leitura, que visa a envolver o leitor afetivamente na realidade da narrativa" (SCHOLLHAMMER, 2011, p. $59)$.

Algumas tendências da crítica literária brasileira têm por escopo, atualmente (século XXI), certas problemáticas e determinadas temáticas 
unidas e separadas por diversos elementos. Um desses elementos consiste na tentativa de compreensão do cenário literário contemporâneo. Desde um célebre ensaio de Antônio Candido (1987), há tentativas de compreender aquilo que o teórico em questão denomina, referindo-se à produção brasileira a partir da década de 1970, como a "verdadeira legitimação da pluralidade":

Resultam textos indefiníveis: romances que mais parecem reportagens; contos que não se distinguem de poemas ou crônicas, semeados de sinais e fotomontagens; autobiografias com tonalidade e técnica de romance; narrativas que são cenas de teatro; textos que são feitos com a justaposição de recortes, documentos, lembranças, reflexões de toda a sorte. (CANDIDO, 1987, p. 209)

Essa justaposição de elementos composicionais tão heterogêneos e essa pluralidade dos textos literários são questões de interesse da crítica e da teoria literárias a partir das obras publicadas nos últimos anos, pois essas narrativas que abordam, com maior premência, dois construtos básicos: representações da violência e textualização contaminadas por códigos de outras linguagens, como, por exemplo, a cinematográfica e a televisiva.

Já Beatriz Resende, indica uma multiplicidade não só na forma, ou no tema, mas também no suporte e no próprio conceito de Literatura. Essa multiplicidade vai além do objeto de criação literária, ela está no pensar a Literatura, visto que há uma convivência de tendências literárias, sem a imposição de uma sobre a outra:

Multiplicidade é a heterogeneidade em convívio, não excludente. Esta característica se revela na linguagem, nos formatos, na relação que se busca com o leitor e - eis aí algo realmente novo - no suporte, que, na era da comunicação informatizada, não se limita mais ao papel ou à declamação. São múltiplos tons, temas e, sobretudo, múltiplas convicções sobre o que é literatura, postura que me parece a mais interessante e provocativa nos debates que vem sendo travados. (RESENDE, 2008, p. 18)

Entre as questões comuns nas e das diferentes manifestações literárias contemporâneas no e do Brasil estão: a presentificação, o retorno do trágico e 
a temática da violência nas grandes cidades. A primeira é apontada não só como uma caraterística estética, e sim como um sintoma para entender a relação do sujeito com seu tempo e como ela é representada no texto literário. Essa primeira questão comum dialoga com a perspectiva de Karl Erik Schollhammer (2011), que entende o presente como "a quebra da coluna vertebral da história, e já não pode oferecer nem repouso, nem conciliação" (SCHOLlHAMMER, 2011, p. 12). Para Resende (2008), esse mesmo elemento é expresso da seguinte maneira:

\begin{abstract}
Diante das novas configurações do espaço geopolítico e de diferente organização do tempo, premido pela simultaneidade, as formações culturais contemporâneas parecem não conseguir imaginar o futuro ou reavaliar o passado antes de darem conta, minimamente, da compreensão deste presente que surge impositivo, carregado ao mesmo tempo de seduções e ameaças, todas imediatas. (RESENDE, 2008, p. 28)
\end{abstract}

A preocupação obsessiva com o presente, tomada como sintoma do contemporâneo que ecoa nas representações artísticas, contrasta com a valoração do passado pelas gerações anteriores e é fulcral na exploração de novas formas literárias, tais como o conto curtíssimo ou microconto (exemplo: a coletânea Cem Menores Contos Brasileiros do Século, organizada por Marcelino Freire).

Para Resende (2008), a constatação de um retorno do trágico (a segunda questão) não é exclusividade da Literatura, pois a tragicidade encontra-se presente em diversos aspectos do nosso cotidiano (vide a exposição de tragédias públicas e particulares na mídia, sobretudo, a televisiva). A autora lembra que, de todos os gêneros da poética clássica aristotélica, o trágico é aquele que se realiza sempre no presente, uma vez que o pathos trágico recai sobre o momento imediato.

Se na maneira formal, o trágico manifesta-se na elaboração de narrativas que trazem não só a matéria trágica - e por isso violenta -, mas também a retomada de conceitos como a inevitabilidade do destino, a escolha 
trágica e a ação que transcorre no presente (seja o presente temporal, seja o da memória, seja o da escritura) na Literatura brasileira contemporânea, o efeito trágico e o realismo extremo, para Schollhammer (2013), retomando Foster, está no paradoxo:

Querendo expressar o inexprimível, presentificar o irrepresentável, indo em direção ao mais repugnante e intolerável da nossa realidade em que a eficiência da experiência se evidencia na impossibilidade da representação. [...] Diante dessa realidade a imagem é entendida por Foster como tela ou biombo que simultaneamente exibe e esconde 0 objeto, nos expõe ao real e nos protege contra ele. Traz para dentro da representação sua manifestação mais concreta da violência, sofrimento e morte, assim encoberta pela imagem ou pela linguagem, simultaneamente inclui indícios que apontam para além da imagem, para o real, através de seus efeitos sensíveis e estéticos (SCHOLLHAMMER, 2013, p. 165).

Tal paradoxo sugere, através da falta de claridade na descrição dos acontecimentos narrados e das meias palavras, um efeito da linguagem que, por meio de repetições na sintaxe e na semântica e de efeitos da linguagem poética, esconde e mostra, expondo e ocultando o "real".

Raymond Willians (2002) aproxima o conceito clássico de tragédia ao nosso tempo atual, sugerindo que aquele deve se estender para além do aspecto fatalista que o impregnou ao longo da história, alcançando a "situação de ameaça e falta de alternativas em que se encontra a humanidade hoje" (WILLIANS, 2002, p. 16); conjectura histórica, social e cultural a qual ele qualifica como trágica. $\mathrm{O}$ autor aludido estabelece uma relação contígua entre a arte e a estrutura social vigente:

No sistema capitalista, o que aparece como ordem é por definição a produção metódica da desordem (desigualdade, humilhação, violência, privação, injustiça), enquanto a desordem a ser necessariamente produzida pela revolução tem por finalidade a criação de uma nova ordem. Outro aspecto da tragédia de nosso tempo é a incompreensão dessa dialética. Decorre desse diagnóstico uma tarefa artística revolucionária: a exposição da verdadeira desordem. (WILLIANS, 2002, p. 16) 
O retorno do trágico está, intimamente, ligado à tematização da violência nas grandes cidades (a terceira questão), sendo o cotidiano o principal cenário: "tudo isso, porém, partindo da banalidade do trágico no cotidiano da grande cidade para se perder e se encontrar por entre caminhos tão indecifráveis como o próprio trágico" (RESENDE, 2008, p. 32).

Mais especificamente sobre as obras de Laub, Maria Zilda Ferreira Cury (2007), no ensaio Novas Geografias Narrativas, distingue-o de seus colegas de geração, particularizando-o, de modo a marcar a sua presença como escritor do presente:

romances como Música anterior, Longe da água e $\mathrm{O}$ segundo tempo, de Michel Laub, cujo discurso, fiapos de lembranças que buscam reconstruir o passado, só o faz como possibilidade de fugir à consciência trágica do presente, num deslocamento "para dentro", para o mundo interior de seus narradores, num voltar-se para um espaço de subjetivação. (CURY, 2007, p. 14)

Um tempo que se arrasta, um tempo que espera, um tempo que rasteja e não alça voos sem antes bater forte contra o chão; um tempo programado para dar errado, um tempo de relógios não digitais, nos quais cada segundo é contado dolorosamente, e o qual se detém nos detalhes (nas minúcias do cotidiano), na busca incessante por explicações, na reconstrução do passado, na necessidade de entender as motivações por trás de certos atos (atitudes) de determinadas personagens e as consequências que conduzem a narrativa e ganham consistência de realidade imposta e impossível de fuga.

Maffesoli (2003) comenta o seguinte sobre essa imobilidade das personagens na Literatura brasileira contemporânea:

Com a sensibilidade trágica o tempo se imobiliza ou, ao menos se lenteia. De fato, a velocidade, sob suas diversas modulações, foi a marca do drama moderno. O desenvolvimento científico, tecnológico ou econômico é a sai consequência mais visível. De modo contrário, hoje vemos despontar um elogio da lentidão, incluindo a ociosidade. A vida não é mais que uma concatenação de instantes imóveis, de 
instantes eternos, dos quis se pode tirar o máximo de gozo. (MAFFESOLI, 2003, p. 8)

É evidente que outros autores abordam a temática do trauma e dos dramas existencialistas. Existem acidentes fatais, escolhas mal feitas, perdas inesperadas e suas consequências em diversas narrativas contemporâneas, mas parece-nos que Laub traz para suas obras outra perspectiva desses traumas: os traumas provenientes de situações já, muito antes, predestinadas. A tragédia de Longe da Água é individual (o mundo não é tão importante quanto a mea culpa pela morte de um amigo) e não diz respeito aos enigmas enfrentados por toda uma geração, ou às problemáticas sociais, ou políticas, pois independem do esforço da personagem em fugir, em fazer escolhas, em romper o cíclico dos eventos que culminam em traumas, ou em traçar outras linhas que não sejam as que parecem já ter sido traçadas, já que sua existência está sob o comando do destino, que é tecido feito um fio nas mãos de uma senhora que sabe o que faz, enrolando e cortando as linhas do desígnio próprio/ único/ ímpar.

É nesse afastamento da lógica do tempo que a obra Longe da Água adequa-se ao que Schollhammer (2013) sugere e diferencia-se de diversas outras. Na transformação do eu em objeto narrado, há uma lógica incontrolável - "apesar do cuidado, não houve como evitar o desfecho" (LAUB, 2004, p. 113) - em tensão com as escolhas individuais - "eu talvez houvesse conseguido uma trégua, uma chance inédita para o reinício" (LAUB, 2004, p. 100).

A partir de um dado momento, tudo o que é narrado já aconteceu, está no passado, mas é esse passado que ditará o presente e o futuro. A personagem para e olha para trás, reconstituindo o passado para enxergar a si mesmo. E é, exatamente, esse passado tido como força motriz para o presente e para o futuro que torna a obra de Laub (2004) como vinculada a tragicidade clássica, com o retorno ao passado para a construção sólida do presente e do futuro, salientando os elementos de uma espécie de neorrealismo na obra literária referida. 


\section{Referências}

BAKHTIN, Mikhail. Epos e o Romance: sobre a metodologia do estudo do romance. In: Questões de Literatura e de Estética: a teoria do romance. 6. ed. São Paulo: Hucitec, 2010.

BENJAMIN, Walter. O narrador. In: . Magia e Técnica, Arte e Política. 7. ed. São Paulo: Brasiliense: 1994.

BÜERGER, Peter; BÜRGER, Christa. La desaparicion del sujeto: historia de la subjetividad de Montaigne a Blanchot. Trad. Agustín González Ruiz. Madri: AKAL, 2001.

CANDIDO, Antônio. A nova narrativa. In: A educação pela noite e outros ensaios. São Paulo: Ática, 1987.

COMPAGNON, Antoine. O Demônio da Teoria: literatura e senso comum. 2. ed. Belo Horizonte: Editora UFMG, 2010.

LACAN, Jacques. O Seminário: Livro 17. O Avesso da Psicanálise. Rio de Janeiro: Jorge Zahar, 1992.

LAUB, Michel. Longe da água. São Paulo: Companhia das Letras, 2004.

MAFFESOLI, Michel. O instante eterno: o retorno do trágico nas sociedades pós-modernas. São Paulo: Zouk, 2003.

RESENDE, Beatriz. Contemporâneos: expressões da literatura brasileira no século XXI. Rio de Janeiro: Casa da Palavra, 2008.

SCHOLLHAMMER, Karl Erik. Cena do crime: violência e realismo no Brasil contemporâneo. Rio de Janeiro: José Olympio, 2013.

. Ficção Brasileira Contemporânea. 2. ed. Rio de Janeiro: Civilização Brasileira, 2011.

WATT, lan. A Ascensão do Romance. São Paulo: Companhia das Letras, 1996.

WILLIAMS, Raymond. Tragédia moderna. São Paulo: Cosac e Naify, 2002. 